\title{
Teaching Creativity Across the Curriculum Through Design Education. Case Studies
}

Gisli Thorsteinsson \& Tom Page 


\title{
Teaching Creativity Across the Curriculum Through Design Education. Case Studies
}

\author{
Gisli Thorsteinsson ${ }^{\mathrm{a}^{*}}$, Tom Page $\mathrm{b}^{\mathrm{b} *}$ \\ ${ }^{a}$ University of Iceland, v/Stakkahlid, 105 Reykjavik, Iceland \\ ${ }^{b}$ Loughborough University, Epinal Way, Loughborough LE11 3TU, England \\ *Corresponding author: cdt@hi.is
}

Abstract

Keywords:

Creativity

Design education

Teaching

Teachers' understanding

Values

Curricula

\section{Zusammenfasung}

Schlüsselworte:

Kreativität

Design Bildung

Lehre

Lehrer Verständnis

Werte

Curricula
This article examines the effectiveness of design as a subject fulfilling its role in developing creativity within students by allowing and supporting creative behaviour and its expression. Creativity in education has been a pressing issue for many countries in recent years, resurfacing as a key topic for discussion, yet the term is still surrounded by ambiguity and discrepancies. This study attempts to establish teachers' understandings and definitions of creativity, outlining their methods for its nurturance through a triangulation of research. The results returned inconclusive evidence of a precise definition agreed upon by the majority of educators, however, multiple themes arose throughout, demystifying the concept and adding to areas of the current body of knowledge. Implications for greater acknowledgement of the creative process rather than exclusive attention to products that abide by restrictive criteria are highlighted as steps in the right direction for the effective development of creativity within design as a subject in educational institutions.

Dieser Artikel untersucht die Wirksamkeit des Designs als Subjekt, das seine Rolle bei der Entwicklung von Kreativität in den Schülern erfüllt, indem es das Verhalten und seinen Ausdruck unterstützt und unterstützt. Kreativität in der Bildung war ein dringendes Thema für viele Länder in der jüngsten Geschichte, wieder einmal wieder als ein Schlüsselthema für die Diskussion, aber der Begriff ist immer noch von Geheimnis und Diskrepanzen umgeben. Diese Studie versucht, das Verständnis und die Definitionen der Kreativität der Lehrer zu etablieren und ihre Methoden der Pflege durch eine Triangulation der Forschung zu skizzieren. Evidenz kehrte unerklärlich von der exakten Definition von einer Mehrheit, aber mehrere Themen entstanden durch, entmystifizieren und Hinzufügen zu Bereichen des aktuellen Wissens. Implikationen für eine stärkere Anerkennung des kreativen Prozesses und nicht ausschließlich auf Produkte, die durch restriktive Kriterien gelten, wurden als Schritte in die richtige Richtung für eine effektive Entwicklung der Kreativität in der Gestaltung als Subjekt, in Bildungseinrichtungen hervorgehoben.

\section{Introduction}

The National Advisory Committee on Creative and Cultural Education (NACCCE) report (1999) describes the term as using 'imaginative approaches' in the context of creative teaching. However, this fails to give a clear definition and rather passes the confusion on to the need to define what it is to be imaginative. Recognising this and referring to the report's description it is not a universal belief, Baer \& Kaufman (2012) note that 'creativity refers to anything' when the product or method is 'original to the creator' and 'appropriate to the (initial) purpose'. In relation, some support the interpretation of a cyclical process, whereby all that is can be classed as an evolution from a previous stage. This then deems notions of creativity as a 'recreation' of that which has been done, given that the route taken to arrive at this destination is entirely unique (Pope, 2005). The authors describes this understanding as 'interpretive replication', in which intercontextual knowledge, collected and arranged in a way singular to a particular individual, is used to achieve a desired goal, regardless whether that goal has been previously reached by way of another's approach.

Opposing schools of thought have argued creativity is originality in the purest form, being an effective method for reaching set goals, entirely unique to human thought, disregarding mere novel application (Ghiselin, 1963). Such speculation favours few in possessing such dexterity, as assuming people are equal in psychological function places a façade over the certainty of unrepeatable identity. Consequently, without acknowledgement of this, Tusa (2003) argues it will 'diminish society's capacity for innovative imagining'.

Comparatively, Montouri (2014) argues that creativity 'avoids premature definitions and categorisations', 'pushing back (the) boundaries' of previous assumptions and potential expectations of what the result produced may be. Expanding on this, Montouri suggests that it is due to such vague understanding that creativity was associated with the Romantic Movement, labelling it as a 'gift' 
only found in a chosen few practicing the arts subjects. Lack of clarity remained for over a century, resulting in the continuum of mystery surrounding the term, with as little as $0.2 \%$ of publications in Psychological Abstracts being based on the subject of creativity (Guilford, 1950).

Although in disagreement upon certain aspects of the phenomenon, such opinions stand together in the understanding of creativity as a type of behaviour which refers to productivity and value of achievement in regard to outcome. Gilchrist (1972) explains the 'prowess' as something within all people, with the ability to be actualised if the right direction in development is taken, along which appropriate opportunities for utilisation can arise. Fromm (1959) supports such considerations, characterising it as the 'capacity' to orientate through activities with a proficient degree of awareness of experience throughout the unravelling process. Similarly, one's control, or lack thereof, over external and internal factors (e.g. environment, emotions) has been contended as potentially a deciding element in the materialisation of their creative ability (Sternberg \& Lubart, 1999). Assuming so, this places the attribute on a multi-dimensional level, adding extreme depth for exploration, which due to limitations, is not feasible to cover in this project. Therefore, a focus on creativity's inclusion in education, particularly in the subject of design, will be further addressed.

\section{Theoretical foundation}

During the 1950s a realisation of the lack of innovation and imagination from university graduates became a cause for concern. Cropley (1995) reported how students were simply applying the 'already known in conventional ways'. With this in mind, many expressed feelings of being 'uneasy about emphasising creativity', contradicting the common sensible procedure to counter the increasing problem, although this failed to cease the newly found sense of encouragement for creativity to be written into curriculums.

The 1960s gave way to a focal shift on creativity and its development in children following the publication of 'Torrance Tests' (Feldman et al., 1994).

Torrance (1962) signifies Guilford's model of divergent thinking as having been the prime basis when designing the test, which opens room for debate as the model's association with testing for creativity is not universally accepted. However, from the standpoint of the institution, this approach seemed particularly appealing due to its practicality and plausibility; therefore, it was widely adopted. Through this, suggestions of taking a quantity over quality approach arose; for example, Ausubel (1964) claimed 'hard-headed educators...adopted highly unrealistic educational objectives regarding the nurturance of creativity'. Wallach (1969) criticised such frameworks, and he became a pioneer in renovating institutional attempts in creative development, pursuing the trait as being domain-specific rather than domain-general.

Fluctuations in belief of importance, along with struggles to perfect the approach, although varying in degree, remain a constant trial faced by educators. Once again, the need for creativity to be developed within students through educational institutions has become a pressing issue, concerning multiple countries (such as the UK, Hong Kong, Australia, Turkey and Singapore), who recognise its potential in contributing to social and economic progress when aiming to thrive in a world of rapid change (Lafci, 2009). The Journal for the Education of the Young Scientist and Giftedness (2012) comments on creativity being richer in the 'golden age' of childhood due to children's 'fewer prejudices' allowing them to 'experiment and give original solutions' to situations they face. Sternberg and Lubart (1999) expand on this thought, suggesting that they begin to 'suppress' these characteristics when enrolling in the educational system, which limits them to 'draw(ing) inside lines'. Further studies by psychological theorists view the grouping of individuals with the hope of coaxing independent creativity as counterproductive, as each student's creativity is a personal phenomenon (Abra \& Abra, 1999). Baer and Kaufman (2012) offer a similar thought, as they explain in their dissection of motivations how 'extrinsic motivation (i.e. a deadline) zooms up' on a student, 'depressing creativity'.

In clear contrast they claim that by 'thinking deeply' (creatively) about content knowledge, it begins to cement itself into the memory; yet they go on to say that to be creative, or indeed think creatively, a significant level of knowledge is needed. Whichever opinion is chosen, it can be approached from two further angles: creativity as being domain-general or creativity as being domain-specific.

Gardner (1983) proposes five constructs of intelligence: verbal-linguistic, mathematical-logical, visual-spatial, naturalist and musical-rhythmic. Often creativity is associated with the ability to produce unique links between such areas, surpassing the rigid limits of common thought or, in the case of educational institutions, strict guidelines between subjects which run as domain-specific, as this is the 'safest and most practical course of action' (Baer \& Kaufman, 2012). The Commonwealth of Australia (2008) holds the same perspective of the skill as 'limited to artistic domains' yet stresses the importance of it being encouraged in students whilst in school.

A further independent platform of belief suggests that the creative process is mainly the product of student exposure to a variety of external factors used to achieve an outcome. Moreover, with this accounting for a larger contribution, creativity has been argued to be something students should study 'distinctively' (Feldman, 1994). Arguably, Cropley's (1999) view of conditions necessary for creativity relate to such thought, as he stresses that emphasis on opportunity for students' expression of personality provides the necessary environment for creative disposition. He expands, describing such freedom as paramount within the 'classroom climate' to effectively engage the three psychological dimensions of creativity: cognitive factors, personal properties and motivation. Instating this approach produces further discrepancies, as school and university students face restrictive marking schemes, with little room in the criteria for such a freedom, by which they are marked subjectively through the marker's understanding of what creativity is. If in disagreement, a lower mark is then given, which has potentially negative effects on the student, as it may belittle Cropley's dimensions of personal properties (e.g. confidence, openness) and motivation. 


\subsection{The role of design as a subject in allowing the expression of creativity}

In the National Curriculum for Design and Technology, the Department for Education UK (2013) states that the purpose of students' study is to offer them an opportunity to use 'creativity and imagination' to solve 'real and relevant problems'. It describes its aim as encouraging children to 'apply and build a repertoire of knowledge' so as to develop them into 'resourceful' and 'capable citizens'. Casakin and Goldshmidt (1999) support this theory in explaining how 'general pre-conditions' of understanding about a given subject are needed to develop 'expertise'. They go on to say how design students need not be taught the skill of analogy, as they already possess the 'cognitive capacity'; rather they need to be guided within this mind frame and become attentive to its potential when problem-solving. Findeli (2001) further expands such thought, suggesting design as a subject offers a place for students to be open-minded, utilising all areas of their intelligence, as 'one cannot act upon a system, only within a system'. This may suggest students cannot effectively be designers by exclusively focusing on the skills learned in a design class; rather they must encompass intellect from a broad range of subjects across the curriculum.

\subsection{Studies in terms of creativity in design education}

Undercutting these hopes discussed above, some comment on lack of enthusiasm from certain teachers in providing an environment where students can explore these qualities alongside the narrow set design briefs as a concern within design and technology (D\&T) as a subject (Rutland, 2004). Further study into this area revealed that 'climate to a fairly large extent is in the hands of the manager', which, in this case, leaves the ultimate responsibility of ensuring suitability for creativity to the teacher and institution (Ekvall, 1996, p. 122). McLellan and Nicholl (2008, p. 4) report that only $57 \%$ of students agree they are allowed to choose the work they do in D\&T, yet $93 \%$ of teachers believed that offering choices was important, highlighting a lack of consistency in perception. The study goes on to report $26 \%$ of said teachers agree it is a 'waste of time letting students work on design[s] in D\&T that ultimately might not work'. Another study, comparing design professionals against design students, found that teachers need to push for more experimentation, supporting risk taking and uncertainty, to build a student's confidence about partaking in the creative process (Klein \& Shragai, 2001). It continues, explaining how professionals organise 'dwell' time for the incubation and development of ideas, often resulting in positive affirmation when revisited, a process overlooked by many educational systems.

Additional argument holds that design as a subject must engage students and teachers through sovereignty in challenging projects and the education of complex skills, allowing for motivated, healthy human function from both parties (Deci \& Ryan, 1985). Yeomans (1990) states that, presently, educational systems confine the student experience and limit staff incitement, consequently decreasing opportunities for creative behaviour, as they are overcome with the academic demand to be suitable for administration. He describes the perceived division between thinking and making, held by most institutions, as 'dangerous' for society, as it is imperative to recognise the link between subject study and subject practice to develop effectively. He provides further thought, suggesting that design as a subject is the most 'appropriate vehicle' in materialising the interests of citizens as both taxpayers and parents. A study by Klein and Shragai (2001) revealed that 'namely everyone can be creative', stating there are 'means to enhance' this skill, which, if true, should be the base for design as a subject's role in the curriculum. A current approach appears to be addressing this, as the Department for Education (2014) states that D\&T assessment will not be on a set of opaque level descriptions but on the essential knowledge, understanding and skills that all pupils should learn'.

\section{Research methodology}

\subsection{Research design and procedure}

The aim of the research was to establish an understanding of creativity across Key Stages 3, 45 and university curricula. The objectives were to:

- Investigate teachers' perceptions of creativity and present overlapping ideas.

- Understand how teachers define creativity and use it within their teaching.

- Explore how teachers cater for creative students in their classrooms.

- Understand whether skills for creativity are taught or developed.

- Look at school and university curricula content and creativity's place within it.

The research questions were as follows:

- How do teachers define or understand creativity?

- Do teachers view creativity as an innate skill or believe it can be developed?

- How do teachers include creativity in their classes whilst working alongside the curriculum? What creative approaches do teachers use in their teaching?

The research was based on an interpretivist paradigm. An interpretivist model is the appropriate avenue of approach for the research subject due to the information gathered being of a qualitative nature (Mead, 1964). It is important to acknowledge that the authors' own understanding of the subject may be reflected through the research and analysis due to their own background in design education influencing the construction of their individual perceptions (Thomas, 2009). Cohen and Crabtree (2006) detail this as transactional or subjectivist epistemology, which suggests individuals cannot separate themselves from their understandings, as these are what forms our realities. The two continue, claiming one's reality is inherently linked to a particular context and therefore can be transformed through re-interpretations and negotiations of new observations in each moment.

In an area governed by subjectivity, the employment of social interaction to achieve a set objective (e.g. an interview) guides participants to a mutual understanding of what is expected, 
resulting in an 'intersubjective consensus' (Popkewitz, 1984). This, therefore, supports the theory of research as being inextricably linked to the researcher's reality, as in that moment it is a collaborative construct of all parties involved. This is an important factor to highlight, as such a variable will distinguish one author's study of research from another's. It is also important to note that due to the abstract nature of the areas this research aims to investigate, such situations are generally 'adequate' or 'efficient' in outlining the depth and clarity of the opinion of the respondent (Glaser \& Strauss, 1967).

A collection of primary research data was attained through a methodological triangulation of both questionnaires and interviews conducted with education professionals from secondary and university levels (Denzin, 1978). This arrangement has been widely affirmed, addressed as the 'hallmark of the good social science researcher' by Thomas (2009). Through this proposed methodology of two constructs, each beneficial in their own right, a variety of results and insights was formed, allowing crossreferencing to provide well-rounded material for analysis.

The participants, teachers and students in secondary education, were given all the required information on the reasoning of the questionnaire and interview and instructions as to what to do if they wished to terminate the exercise at any point or wished for the content provided by them to be removed and/or destroyed.

\subsection{Measures}

Questionnaires were used first as an instrument for the data collection. Questionnaires are widely accredited in the social sciences as providing an opportunity for information to be gathered without the presence of the researcher, thus allowing for an honest, personal response (Thomas, 2009). Open-ended questions formed the essence of the questionnaire, the reasoning for this being that the research aims to establish respondents' understandings, which can be best achieved with an invitation for free comment (Cohen, Manion \& Morrison, 2011). The questions' wording was then discussed with a project supervisor and piloted with a teaching professional to ensure that the aims and objectives could be met with appropriate responses. The option to provide date of birth was included on the questionnaire to allow for comparison with their years of teaching, which aided assumptions on whether or not respondents' had likely worked in industry before their career in teaching and how, if at all, this may have affected their opinions. Of the 20 questionnaires distributed in Finchley Catholic High School, eight responses were received. Four further responses were received through individual contact with university lecturers.

To delve deeper into the respondents' understandings and move further towards the clarification of themes which arose throughout the information attained within the questionnaires, interviews were assigned. This was carried out with three participants, matching the previously proposed criteria as best as possible. The interviews followed a semi-structured set of questions, offering the researchers the opportunity to pursue opinions and/or attitudes displayed when discussing the interpretive sociology (Hopf, 2004).
Three interviews, which took place on 5 March 2015, were conducted with teachers in secondary education, and each lasted approximately 20 minutes. Due to ethical considerations and a conformed respondent request, the interviews were transcribed. However, although this meant that important data regarding reactions and body language were not collected, the researcher used such behaviours to aid decisions on which avenues of discussion to follow during each interview to elicit detailed authentic information. The combination of both a questionnaire and complementary interview allowed for a more balanced acquisition of complex results along with opportunities to better understand and, in turn, then organise shared ideas or discontinuities into thematic categories.

Where possible, results were quantified and tabulated to allow for effective and practical analysis. Wording has been categorised into synonyms and opinions so as to be assessed for themes and patterns and indexed accordingly into set codes. Such a process provides opportunities for the effective refinement, organisation and comparison of the vast subjective understandings received from each research process (Gibbs, 2007). The findings will then be triangulated for further substantiation and assurance of reliability (Golafshani, 2003). Variables which may have potentially intervened will be reported and considered if they appear to emerge as a particular pattern, followed by a discussion in regard to the extent to which they may have impacted the produced results.

When the analysis of results has been completed according to the findings, potential generalisations and assumptions about the wider population may be made (de Vaus, 1986). However, due to the limitations of opportunistic sampling and low number of respondents, each generalisation will be critically assessed for credibility in the discussion (Robson, 2011).

\section{Results}

\subsection{Results from questionnaires}

Table 1: Participants who answered the questionnaires and their sex and professional area

\begin{tabular}{|c|c|c|c|}
\hline $\begin{array}{l}\text { Questionnaire } \\
\text { Participants }\end{array}$ & Subjects & Sex & $\begin{array}{c}\text { Worked in Industry } \\
\text { before teaching } \\
\text { (Assumption) }\end{array}$ \\
\hline Teachers (8) & $\begin{array}{l}\text { Business } \\
\text { / English } \\
\text { / ART } \\
\text { / D\&T }\end{array}$ & $5 \mathrm{M} / 3 \mathrm{~F}$ & 4 \\
\hline Lecturers (4) & $\begin{array}{l}\text { Science } \\
\text { Business } \\
\text { / ART } \\
\text { / P.E. } \\
\text { Design (various } \\
\text { areas) }\end{array}$ & $3 \mathrm{M} / 1 \mathrm{~F}$ & 3 \\
\hline
\end{tabular}

To determine patterns in the participants' understandings and definitions of creativity, the answers for questions 1 and 2 were tabulated to allow for the quantification of recurring words associated with the term. Throughout the questionnaire, many 
participants mentioned additional words when addressing the term, which were also counted, abiding by Cohen and Crabtree's (2006) claim of understanding being a constant development through each moment and its context. Thereby, the results were then easier to analyse in regards to making generalisations of a teacher's or lecturer's perception of the word. Due to the vastness in response, particular words were grouped together according to their dictionary definition, as many were synonyms of each other.
This allowed for a closer degree of clarification on key features related to the word and emerging trends, regardless of the synonym used, by accommodating varying vocabularies. Additionally, responses from teachers and lecturers are presented separately, providing room for comparison.

Table 2: Results from questionnaire Q1

\begin{tabular}{|c|c|c|c|c|c|}
\hline Questionnaire -Q1 & $\begin{array}{l}\text { Mentioned in Q1 } \\
\text { Teachers }\end{array}$ & $\begin{array}{c}\text { Mentioned otherwise } \\
\text { Teachers }\end{array}$ & $\begin{array}{l}\text { Mentioned in Q1 } \\
\text { Lecturers }\end{array}$ & $\begin{array}{l}\text { Mentioned otherwise } \\
\text { Lecturers }\end{array}$ & Total \\
\hline Innovative & 2 & 0 & 1 & 0 & 3 \\
\hline $\begin{array}{l}\text { Challenging traditin } \\
\text { /Outside the box } \\
\text { /Risk Taking }\end{array}$ & 3 & 1 & 4 & 3 & 11 \\
\hline $\begin{array}{l}\text { Original } \\
\text { /Unique } \\
\text { /Individual } \\
\text { /Novel } \\
\text { /New }\end{array}$ & 5 & 2 & 5 & 4 & 16 \\
\hline $\begin{array}{l}\text { Adaptable } \\
\text { /Flexible } \\
\text { /Survive }\end{array}$ & 2 & 1 & 1 & 1 & 5 \\
\hline Different & 1 & 1 & 2 & 2 & 6 \\
\hline Thought process & 0 & 0 & 2 & 1 & 3 \\
\hline Experimentation & 1 & 1 & 1 & 1 & 4 \\
\hline Imagination & 0 & 0 & 2 & 3 & 5 \\
\hline $\begin{array}{l}\text { Behaviour } \\
\text { /Attitude }\end{array}$ & 1 & 1 & 0 & 1 & 3 \\
\hline
\end{tabular}

As can be seen from the results, the pattern most common is the view of creativity involving something original, unique, individual, novel or new, with 'new' accounting for 7/16 mentions. Closely following are opinions of creativity being linked to a 'thinking outside the box' approach, which accounted for 5/11 mentions. Aside from the 'adaptable' and possibly the 'innovative' groups, none of the others are inherently linked to a positive product or achievement, arguably sharing undercurrents of a description rather a process or approach. However, although there is general consistency throughout in regards to the correlation of answers provided, only one of the participants (lecturer) explicitly put forward the term as being a thought process or the use of imagination.

Table 3: Results from questionnaire Q3

\begin{tabular}{|l|c|c|c|}
\hline \multicolumn{1}{|c|}{ Questionnaire - Q3 } & Teachers (8) & Lecturers (4) & Total \\
\hline Creativity is an innate ability, some are born with. & 4 & 0 & 4 \\
\hline Creativity is a capacity all are born with. & 4 & 4 & 8 \\
\hline Creativity can be taught/developed. & 7 & 4 & 11 \\
\hline
\end{tabular}

The same process of tabulating results where possible for quantification was then applied for the first section of the results for Question 3. Once again, teachers and lecturers were separated for comparison. The quantified results show clear disagreement in creativity being seen as something those who possess it were born with and it being seen as a potential within all humans in the responses from the teachers. Comparatively, all lecturers held the opinion of creativity being a capacity within all. Further, all bar one respondent agreed with the possibility of creativity being taught or developed. Many expanded on their response, highlighting the key role of a student's environment as a deciding factor for such learning and development. One lecturer went as far as to provide a metaphor of creativity being like a 'muscle', implying potential for strengthening and growth through correct 
exercise, with another claiming all nature itself is creative, as it must be to survive.

Question 4 sought findings of a completely qualitative nature, therefore removing the opportunity to quantify and tabulate. However trends and patterns did arise, revealing common methods for catering for creative students whilst working alongside a set syllabus. A total of $5 / 8$ of the respondents who were teachers along with $1 / 4$ who were lecturers commented on allowing relative freedom of individual expression at the beginning of a project, promoting confidence and increasing the interest of the student, which they then work on refining to meet the criteria of the syllabus. Another trend arose, with 2/8 teachers and 2/4 lecturers mentioning the use of suggestion and encouragement going beyond the set project, asking questions that aim to entice imaginative responses and build confidence in conviction and risk taking.

Question 5 prompted respondents to view themselves as creative in their teaching in an attempt to encourage confident descriptions of teaching methods they use and believe to be an expression of this. Strong trends surfaced deeming the need for adaptability in regards to the use of 'different' methods for varying student personalities to be the paramount approach when teaching creatively. This was explicitly mentioned by two participants from each group. Arguably, this was further supported by repeated mentions of using a range of tasks and technologies to effectively deliver the subject to all students, engaging rational, logical, kinetic and visual learners. One teacher suggested challenging a student's ideas and understandings is their own way of teaching creatively, as through this they claim it can 'open their thinking', relating back to the recurring definition in Question 1 of creativity as 'thinking outside the box'. In contrast, one of the lecturers stood in complete disagreement to the opening statement of the question ('All teachers are creative, they have to be'), stating their teaching methods are not creative but rather 'tried and tested'. Furthermore, they offered advice, articulating the need to 'not confuse being creative with creative teaching'.

\subsection{Results from the interviews}

Three interviews were conducted with participants from each of the $0-3,4-7$ and 12-15 years of experience categories in an attempt to determine whether or not differences in understandings and methods used may have subsequently been affected by level of national interest at the time. All three were males, had previously worked in an industry related to D\&T and now taught the subject in Key Stages 3 and 4 alongside teaching Product Design at the A level. Participant 1 (12-15) had a degree in Product Design and a previous career background in engineering. Participant 2 (4-7) had a degree in Product Design and a previous career background in a variety of design disciplines, having also lectured on Product Design for two years at the University of Leeds. Participant 3 (0-3) had a degree and a previous career background in architecture.

Question 1 asked whether or not Design as a subject in the curriculum actually allowed students to be creative. Participants 1 and 3 expressed similar opinions on programmes of study in Key Stage 3 being restrictive in terms of creative teaching and output, as they stemmed from more of a theoretical base covering a broad range of areas in the subject. Participant 3 commented on how this directs the curriculum away from creativity and toward a 'factual and informative' process. Participants 1 and 3 continued in agreement, explaining how Key Stages 4 and 5 allow 'greater opportunities to be creative', as projects 'come from the individual', giving them 'ownership' of the project. The two provided further responses, stating they do believe design allows for creativity, with the optical character reader (OCR) syllabus offering many marks when exercised. However, Participant 3 went on to say that teachers develop a sense of 'fear' in these stages, as a lack of control over these freedoms often reflects badly in academic performance; therefore the process is often diverted back towards 'box ticking'.

Comparatively, Participant 2 made no comment on the curriculum itself nor on a set syllabus; instead he reported on how although programmes of study do make creativity sound 'exciting', they only concern its ability to produce results and products that may contribute economically to the country rather than creating an 'environment for creative patterns of thought and opportunities'. He continued, noting that design as a subject is a template, open to interpretation by institutional management, who often show little interest, therefore 'falter[ing]' the nurturance of their students' creativity.

Question 2.i invited participants to expand on such views in regards to increasing the involvement of creativity in the curriculum and how this may have affected their opinions over time. Participant 1 responded by claiming that involvement in Key Stage 3 had 'mainly stayed the same', providing base knowledge to be used later on, yet believes it has been 'increased and encouraged' in Key Stages 4 and 5. Participant 3 believes little change has occurred although there does 'appear to be a shift in this direction'. Participant 2, once again, gave response from a completely different angle, explaining how his generation grew up in the era of the Keele Project, which focused on how to effectively produce designers. He continued, suggesting that it is due to this generation now being in influential positions that such attempts to develop these skills are being revisited and perceived with upmost importance.

Question 2.ii probed deeper into this area, seeking examples of how each participant has adapted to such changes. Participant 1 detailed the use of new technologies such as interactive white boards, flip-boards etc. within his teaching, expanding methods for delivery to cater for the 'modern student', although he did point out that the content delivered is mainly the same. Participant 2 stated he feels that during his time teaching, nurturing creativity has become increasingly difficult, as the time that is needed to do so is often supressed to ensure the completion of recording statistics, facts and figures to increase academic success. He believes that this is what is 'holding back the development of many students'. He remarked that this is a drain on a student's energy, leaving them unfit to thrive in an exercise driven by levels of relaxation and mood. Countering this, however, he explained how he has 'adapted by being selective and tries to outwit the system'. He expanded on how he does this in his response to Question 2.iii. Participant 3 gave little in response, explaining how he 'attempt [s] to encourage 
creativity, which he has found becomes futile as academic success, is favoured.

Question 2.iii raised the issue of how to cater for creative students in the classroom whilst meeting the demands of the syllabus. Participant 1 took the approach of promoting independence through beginning a project with students having free reign on choice of idea. He explained how this results in enthusiasm as the student chooses a subject of interest, which is the only way a student can be at their most creative. Once a direction is taken, he begins to 'stretch' their ideas and opinions to develop a refinement of how such a solution would work. Participant 2 gave a similar answer, as he provides extra opportunity during his personal time for outside work and development, where he questions the student's work, making suggestions and links to the wider subject area to better round them with a broader knowledge for the ideation of appropriate solutions. Participant 3 based his answer on marking the work of a creative student, re-emphasising how he encourages creative effort and rewards students who have shown this by taking risks through their design process rather than exclusively marking the end product.

\section{Discussion}

\subsection{Defining creativity}

The literature review began by stating the NACCCE's (1999) ambiguous description of creativity, which can be viewed as more closely related to a purposeful process with some value in the outcome than simply a product of high achievement. They perceive 'originality' and 'value' as two out of four equally accounting factors embodied within creativity, acknowledging the subjective nature of evaluating this, yet they fail to outline how the 'value' of produce will be determined fairly. Following this, they say 'creativity has obviously to do with producing something original'. Studies from this project found close relation, as grouped synonyms of the word 'original' governed respondents' definitions of creativity, yet neither the NACCCE's, the respondents' nor the dictionary definitions of the words in the synonym group explicitly mention level of achievement of the outcome.

Branching arguments focused on whether originality was concerned with being new in the eyes of the creator(s) or new to human thought entirely. Baer and Kaufman (2012) and Pope (2005) support the former, agreeing that as long as the product meets previously set conditions, it is creative. Some of the results found were supportive of this view, revealing that respondents linked creativity to adaptation, flexibility and survival, each more closely related in definition to recreation than creation. However, once again, there is no definitive process in determining how well conditions are met or differentiating between what it is to survive and what it is to thrive. From these results, opinions of creativity being only a process or product of original human thought can be ruled out.

Montouri's (2014) view of assumption and expectation as 'boundaries' likely to be broken when creativity ensues was also found to have recurring support, with respondents repeatedly referencing creativity as 'thinking outside the box' or 'risk taking' by 'challenging tradition'. Throughout the research, just one indication of product or product value was given, suggesting the definition resides in the area of process. The respondent distinctively expressed such words, possibly implying Gilchrist's (1972) definition as a 'potential', being the better suitor, as the majority of respondents agreed creativity is a capacity all possess.

\subsection{Creativity in education}

Fromm's (1959) views of awareness of experience and intercontextual links were found to be determining factors in such a potential being realised, possibly explaining the frequent view of creativity seemingly being more apparent in one individual than in another. The results from all the lecturers supported this angle of opportunity for growth to be common in all humans, yet a clear divide in the teachers' opinions was found, as half believed it was a talent only existent in some, reinforcing openness to interpretation. It was further established that all (bar one respondent, who cannot be included simply because a response was not provided) believed in the capability of creativity being developed. Bearing in mind that to develop the means to 'improve' or 'advance', CastroFajardo et al.'s (2014) comment on childhood being a 'golden age' of richness in creative behaviour would imply amplification throughout schooling if educational institutions actually developed creativity. However, it was found that Sternberg and Lubart's (1999) suggestion of such behaviours receiving incremental suppression once children enter school was supported by the teachers, claiming they struggle to encourage students to "think outside the box' whilst the syllabus requires them to 'draw inside lines'. Arguably, this may be the case when considering Baer and Kaufman's (2012) remark on the necessity of substantial knowledge to express creativity in a given area, presenting the issue of schools needing to provide sufficient education in multiple areas to ensure they cater for each individual. The research findings outlined the opportunity for individuality to be regarded as highly important yet agreed with Ausubel's (1964) consideration of current approaches to doing so as 'unrealistic', as demand for higher grades, seemingly achieved through quantity over quality approaches, restricts this.

Expanding further, respondents predominantly held the understanding of creativity being domain-specific as opposed to the common institutional understanding as being domain-general, a system suggested to be detrimental towards individual actualisation (Abra \& Abra, 1999). Acknowledging this, the ability to adapt methods of teaching to meet the differing needs of students was repeatedly emphasised as being creative by respondents, aligning with Cropley's (1999) and Ekvall's (1996, p. 122) advice to realise the importance of the correct environment and climate. Opinions in the findings further expressed that when such a median is found, students will gain confidence in themselves and their work, with increased levels of interest, inducing progression in selfdevelopment. Extensively, support for Cropley's (1999) warning that failure to categorise this as academic success and not awarding marks appropriately often lowers student confidence in creative expression surfaced as being a present reality viewed by multiple respondents. However, this should not be equally assumed of all institutions, as the majority of respondents were from the same 
workplace, and it is widely recognised in both this study and others that approaches to education and the extent to which certain areas are valued often varies.

\subsection{The role of design as a subject in allowing the expression of creativity}

As previously mentioned, it is said that to be creative, and indeed acquire expertise, 'general pre-conditions' concerning knowledge relative to the subject are fundamental (Casakin \& Goldschmidt, 1999). This reason is a likely justification for Key Stage 3 programmes of study to have been deemed restrictive in content by participants as well as the Department for Education UK (2013) stating the intent for the subject to expand the students 'repertoire of knowledge'. Later findings revealed it was generally agreed that Key Stages 4 and 5, through allowing students choice in projects, did provide some space for creativity but were viewed as limited and enigmatic. One participant described this as being the result of poor judgment from society, as its main concern is proven economical contribution, overlooking the benefits of an environment which nurtures creative thought due to its irregularity. Such speculation refers back to Cropley's (1995) point of design students being taught how to efficiently navigate machines but lacking awareness of and experience in successful design processes, undercutting the Department for Education UK's (2013) aim to produce creative solutions for 'real and relevant problems'.

Participants' responses go on to coincide with Rutland's (2004) claim that D\&T departments contain unenthusiastic teachers, as it was found that the management of institutions often has 'little interest' in anything other than academic results, downplaying developments in the subject syllabus and methods of delivery as content remains generic. Such findings could explain McLellan and Nicholl's (2008, p. 4) data revealing a significant number of teachers disregarding projects in D\&T that lack clarity, as participants in this study felt pressured into 'ticking [criteria] boxes' and consequently believed this held back their students.

Recent updates saw the Department for Education UK (2014) state that grade descriptors would no longer be 'opaque', yet the participants disagreed on this being materialised. Klein and Shragai's (2001) highlighting of the need for increased support in process and experience does not seem to have been actualised either, as one participant openly admitted to having to 'outwit the system' to effectively promote independence, build confidence and increase enthusiasm to better round a student as a proficient designer. Similarly, it was found that another participant in agreement with the need to implement such support practiced this by awarding fair marks for creative effort rather than exclusively to outcome.

\subsection{Overview}

Both primary and secondary research further reinforced the fact that creativity is ambiguous in exact definition due to varying individual interpretations. However, relative themes do arise when investigating perceptions, some of which were given support through the findings in this study, allowing for easier understanding and comparison. Despite this, terms put forward from both theorists in the literature review and the respondents of this project's study were usually unclear in their own definitions and subjective to the individual concerned. The mystery continued, as uncertainty and conflict were apparent in the process debate, the product debate or both, with considerable theory supporting each angle. Once again, it is an arguable view, but the perception of creativity as a process was found to be prevalent, supported by much of the current literature, the study results and the authors. Furthermore, some of the chosen wording, along with the context in which it was used, often contradicted that of another opinion, which illustrated the dangers surrounding the expression of creative behaviour from an individual with an opinion that opposes the opinion of their external environment. As a result of this, although many associations were clarified as common thought, the research failed to find a majority view, leaving the term indefinite.

The evidence mainly found creativity to be seen as a capacity within all, which had a variety of techniques available for it to be enhanced, yet it was put forward that current educational systems have failed to administer such processes. Considering this, it cannot be overlooked that core knowledge and skill are needed to work in a field effectively before creativity can be exercised. It was found that institutions are believed to have misjudged this, hoping to teach creativity through a syllabus and mark it against a fixed criteria rather than teaching skills followed by furnishing an environment where individuals and creative expression may flourish. The authors would be in support of such a portrayal, as personal experience was reflective of such dictatorship over the enjoyable freedom of what creative expression should be. It was communicated that too much focus is placed upon end results equating to academic success, misinterpreting the process of development as a constant throughout creative behaviour. Furthermore, if all work is marked against a set criteria of what is known or expected, and something completely new but unproven is submitted, effective assessment cannot be completed if it is against the preconceptions of the former, restricting academic success to only what is already known. The evidence mainly found creativity to be seen as a capacity within all, which had a variety of techniques available for it to be enhanced, yet it was put forward that current educational systems have failed to administer such processes. Considering this, it cannot be overlooked that core knowledge and skill are needed to work in a field effectively before creativity can be exercised. The literature reported several projects that employed different methods for improving creativity. The majority of these were curriculum development programs, rather than research based, largely focusing on measuring the quality and quantity of the use of idea generation; for example, the Torrance Tests of Creative Thinking. The findings in the reported studies involving young students indicated that the development of creativity skills through training can improve divergent-thinking performance. The majority of the studies incorporated brainstorming and this highlights the importance of brainstorming within the creative process. The studies also indicated that training aimed at improving creativity can be effective for all students, including the gifted and the disabled. Furthermore, the literature indicated that the use of computer software to support creativity is effective, with regards to improving students' attitude to learning. 
The literature showed there are alternative system in assessing and marking creativity by teachers. Otherwise creativity development would just be a hidden process of education that could not be measured. There are three main methods to assessing creativity in students' learning or by product; by process and through a mixture of these. They comprise visual and graphical representations as designs, paintings, sketches, drawings, photographs, videos, computer animations; physical and virtual models and constructions. They can also consist of performance as theatre peace, simulation, role play, dance, song and live or recorded presentation. In higher education products might consist of essays and numerous forms of writing counting, diaries, reports and reflective logs, poems, posters, the products of electronic discussions; the results of problem working, independent and collaborative projects in design and synthesis, laboratory or field notebooks.

Processes can be examined within which creative. They may have been individually created and self-directed or be built collaboratively or involve elements of both. Some may be established within pedagogy as problem based learning, design process, role play or they may constitute rehearsals aimed at creative presentation. Process can be measured through direct observation of pupils, through video or tape records or diaries, through reflective individual accounts supported by evidence that authenticates the account.

In the lower Key Stages such restrictions are appropriate, as knowledge and skill must be attained through strict and efficient practice, yet it appears institutions forget that this is not the end all and be all. The continuum of such systems into later academic life is inappropriate, as it incapacitates the provision of an environment with opportunities for individual creativity. This then is the reasoning for the production of merely 'capable' designers being ill-equipped and slow in discovering opportunity for social or economic leaps, which are, as Gilchirst (1972) says, usually realised and applied by creative individuals. This appears to be due to misinterpretation and an ineffective approach towards the development of creativity on behalf of the institutions, as it was found students do not perceive D\&T projects as having substantial freedom for pure creativity. If so, then it will require insightful change, understanding that it is the students' perception that is paramount, as only once their needs are met, and they are comfortable and interested in the meaningful challenges set, will they generate and realise clever solutions and become creative designers.

\section{Conclusion}

Concluding this study, understandings of creativity have been established to be broad in range between individuals, with some opinions opposing others, and a sense of mystery regarding creativity can be said to still surround the word. This is apparent even between directly linked parties, such as the Department for Education UK, its educational institutions and their teachers. It was found that the curriculum does show intent to nurture creativity, but due to its and the set syllabus' interpretations being different to those of many teachers and their students, the institutions currently appear to be failing to accomplish this. Much of the research indicated that creativity is more closely linked to process than product, and therefore project processes should be celebrated as academic successes, understanding that the key development of such processes lies within support, guidance and opportunity. Although D\&T as a subject and programme of study appeared to be struggling to actualise this, it has clearly gained the recognition of some design teachers, who took the initiative to step ahead of the curriculum's current misjudgements, informing students of the need for experimentation and awareness of experience to enhance their creative abilities.

\section{References}

Abra, J, \& Abra, G. (1999). Collaboration and competition. In M. A. Runco \& S. R. Pritker (Eds.).

Encyclopedia of Creativity (pp.283-293). San Diago: Academic Press.

Ausubel, D. (1964). Creativity, General Creative Abilities, and the Creative Individual. Bulletin of the Council for Research in Music Education, 1(3), p.i-v.

Baer, J \& Kaufman, J. C. (2012). Being Creative Inside and Outside the Classroom. Rotterdam: Sense.

Casakin, H. \& Goldschmidt, G. (1999). Expertise and the use of visual analogy: implications for design education. Design Studies. 20(1), 153-175.

Castro-Fajardo, L., E., Santamaria, A., Bernal-Hernández, K. L. and García-Cepero, M. C. (2014). How Do Educational Professionals Understand Creativity? A Study of the Implicit Theories on Creativity in A Sample of Educators. Journal for the Education of the Young Scientist and Giftedness. 2(2), 41-48.

Cohen D, \& Crabtree, B. (2006). Qualitative Research Guidelines Project. Available at: http://www.qualres.org/Homelnte-3516.html, [accessed on 12/03/2015].

Commonwealth of Australia (2008). Report of the Australia 2020 Summit Creative Australia. Canberra: Department of Prime Minister and Cabinet.

Creativity: is it on the Key Stage 3 (11 -14 years) Design and Technology (D\&T) Agenda?, 1-2. Available at: https://dspace.lboro.ac.uk/2134/2883 [Accessed 13/03/15].

Cropley, A. J. (1995). Fostering creativity in the classroom: General principles. In M. Runco (Ed.), The creativity research handbook, Vol.1. Cresskill, NJ: Hampton Press.

Cropley, A. J. (1999). Education. In M. A. Runco \& S. R. Pritker (Eds.), Encyclopedia of Creativity, 283-293. San Diago: Academic Press.

de Vaus, D. A. (1986). Surveys in Social Research. London: Allen \& Unwin.

Deci, E. \& Ryan, R. (1985). Intrinsic motivation and selfdetermination in human behavior. New York: Plenum.

Department for Education (2013). Design and technology programmes of study: key stage 3. Available at: 
http://www.nationalarchives.gov.uk/doc/open-governmentlicence/, [accessed on 06/01/15].

Department for Education (2014). D\&T National Curriculum for England 2014. Available at: https://www.data.org.uk/foreducation/curriculum/dt-national-curriculum-for-england-2014/ [accessed on 19/03/15].

Denzin, N. K. (1978). Sociological Methods. New York: McGraw-Hill.

Ekvall, G. (1996). Organizational climate for creativity and innovation. -

European Journal of Work and Organizational Psychology, 5 (1), 118123. Available at:

http://www.academia.edu/673511/Organizational_climate_for_crea tivity_and_innovation [accessed on 19/03/15].

Feldman, D., Csikszentmihalyi, M. and Gardner, H. (1994). Changing the world. Westport, Conn.: Praeger.

Findeli, A. (2001). Rethinking Design Education for the 21st Century: Theoretical, Methodological, and Ethical Discussion. Massachusetts Institute of Technology Design Issues. 17 (1), 5-10.

Fromm, E. (1959). The creative attitude. In H. H. Anderson (ed.). Creativity and its Cultivation. New York.

Gardner, H. (1983). Frames of Mind: The Theory of Multiple Intelligences. New York: Basic Books.

Ghiselin, B. in Taylor, C. and Barron, F. (ed.), (1963). The creative process and its relation to the identification of creative talent. New York: Scientific creativity.

Gibbs, G. (2007). Analysing qualitative data. Los Angeles: SAGE Publications.

Gilchrist, M. (1972). The Psychology of Creativity. Melbourne: Melbourne University Press.

Glaser, B. \& Strauss, A. (1967). The discovery of grounded theory. Chicago: Aldine Pub. Co.

Golafshani, N. (2003). Understanding Reliability and Validity in Qualitative Research. Qualitative Report 8(4), 597-606.

Guilford, J. P. (1950). Creativity. American Psychologist, 5(9), 444454.

Hopf, C, in Flick, U. et al. (2004). A Companion to Qualitative Research. London: Sage Publications.

Klein, N. \& Shragai, Y. (2001). Creativity and the design approach: a proposed module. IDATER Conference, Loughborough: Loughborough University.
Lafci, D. \& Crouch, C. (2009). Subjectivity, creativity and the institution. Boca Raton: Brown Walker Press.

McLellan, R. \& Nicholl, B. (2008). 'The importance of classroom climate in fostering student creativity in Design \& Technology lessons'. In Norman, E.W.L. \& Spendlove, D. (eds.). The Design and Technology Association International Research Conference. Wellesbourne: The Design and Technology Association, pp. 29-39.

Mead, G. H. (1964). On Social Psychology. Chicago: University of Chicago Press.

Montouri, A, (2014). Educating for Creativity, World Futures: The Journal of New Paradigm Research, 70(5-6), 338-342.

N.A.C.C.C.E. (1999). All our futures: creativity, culture and education. London: DfEE.

National Advisory Committee on Creative and Cultural Education. (1999). All Our Futures: Creativity, Culture and Education. London: DFEE.

Pope, R. (2005). Creativity. London: Routledge.

Popkewitz, T. (1984). Paradigm and ideology in educational research. London: Falmer Press.

Robson, C. (2011). Real world research (3rd ed.). West Sussex: Wiley and Sons.

Rutland, M. (2004). DATA International Research Conference 2004 on Creativity and Innovation.

Sternberg, R. \& Lubart, T. (1999). Handbook of Creativity. Nueva York: Cambridge University Press.

Thomas, G. (2009). How To Do Your Research Project. Thousand Oaks: SAGE Publications Ltd.

Torrance, E. (1962). Guiding creative talent. New York: Prentice-Hall.

Tusa, J. (ed.) (2003). On Creativity: Interviews Exploring the Process. London: Methuen.

Wallach, M. \& Wing, C. (1969). The talented student. New York: Holt, Rinehart and Winston.

Yeomans, M. (1990). The Future of Design in Further and Higher Edcuation. In Thistlewood, D. 